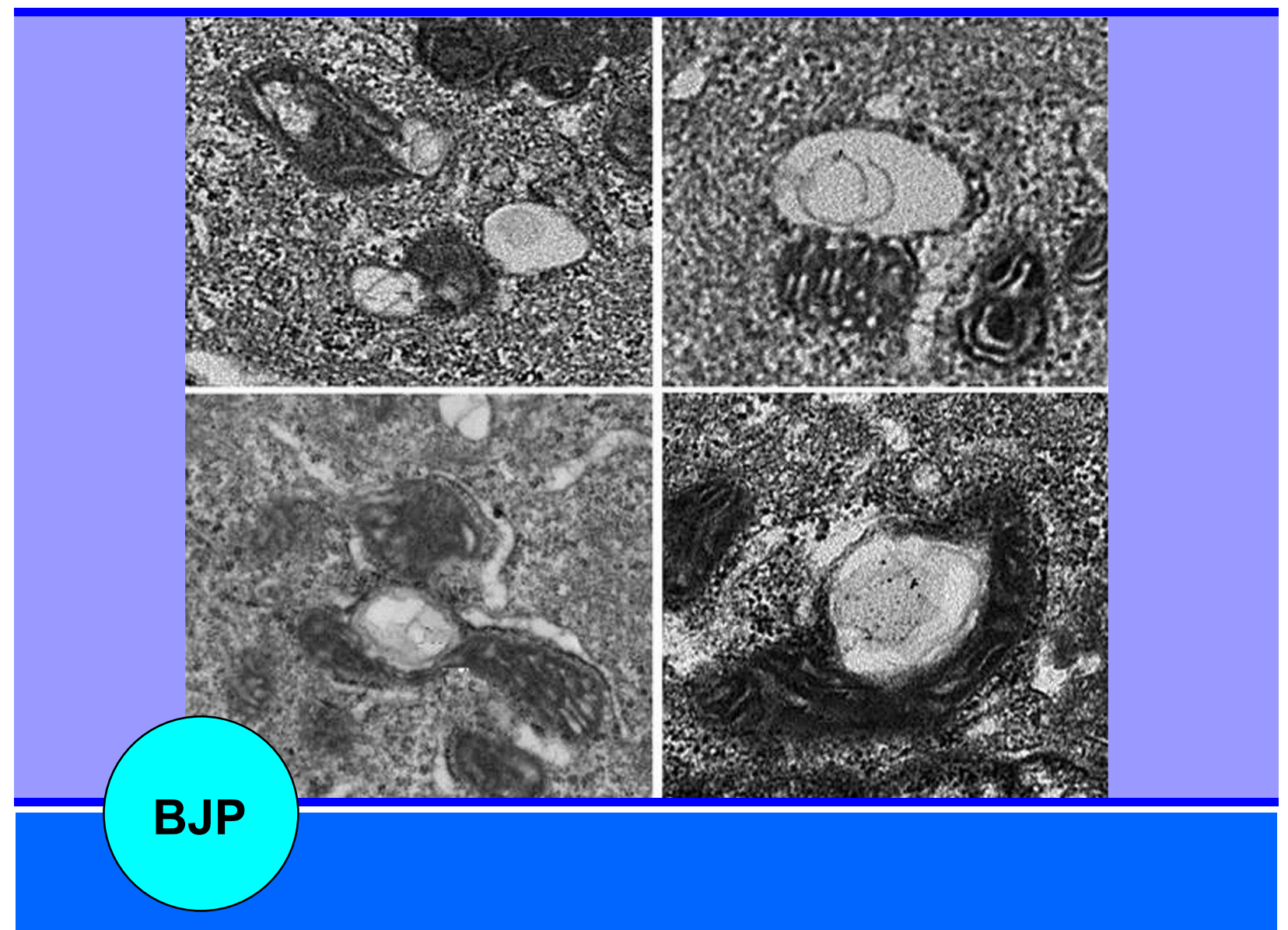

Bangladesh Journal of Pharmacology

Research Article

\title{
Vernolepin regulates apoptosis and autophagy via microtubule for- mation in ovarian carcinoma cells
}


1983). It shows platelet anti-aggregating properties (Laekeman et al., 1985) and is also an irreversible DNA polymerase inhibitor (Clayde, 2005) hence may have antitumor properties. In the present study, we investigated the effect of vernolepin on autophagy and cell death in ovarian carcinoma cells.

\section{Materials and Methods}

\section{Reagent}

Vernolepin, acridine orange (AO), monodansylcadervarine (MDC), 4,6-diamidino-2-phenylindole (DAPI), 3-methyladenine (3-MA) and rabbit polyclonal antibody against LC3 were purchased from Sigma-Aldrich (St. Louis, USA). Lipofectamine 2000 was obtained from Invitrogen (Carlsbad, CA, USA) and Annexin V-FITC Kit from Bender MedSystems (Vienna, Austria).

\section{Cell lines and culture}

OVCAR-3 and SK-OV3 cell lines were obtained from The Cell Bank of Type Culture Collection of Chinese Academy of Sciences, Shanghai Institute of Cell Biology (Shanghai, China). The cells were maintained in Dulbecco's modified Eagle medium supplemented with $10 \%$ fetal bovine serum containing penicillin 100 units/ $\mathrm{mL}$, streptomycin $100 \mathrm{mg} / \mathrm{mL}$ and 10\% FBS (PAA).

\section{CCK-8 assay}

In 96-well plates $1 \times 10^{5}$ cells/well were distributed. The plates after incubation for 12 hours were treated with either DMSO or different doses of vernolepin for different time periods. To each well $10 \mu \mathrm{L}$ of CCK-8 solution (Dojindo Laboratories) was added. The plates were incubated for 1 hour followed by measurement of absorbance at $450 \mathrm{~nm}$ using a microplate spectrophotometer (BIO-RAD xMark).

\section{DAPI staining}

In 96-well culture plates the cells treated with vernolepin were fixed with $4 \%$ paraformaldehyde for $20 \mathrm{~min}$ at $37^{\circ} \mathrm{C}$. The cells were then stained with DAPI for $20 \mathrm{~min}$ and observed under the fluorescence microscope (OLYMPUS IX71).

\section{Analysis of apoptosis and cell cycle arrest using FACS}

The OVCAR-3 and SK-OV3 cells onto 6-well plates were treated with DMSO or vernolepin for 24 or 48 hours after incubation for 12 hours. The cells at a density of $3 \times 10^{5} / \mathrm{mL}$ were washed in PBS and suspended in binding buffer. Annexin V-FITC $(5 \mu \mathrm{L})$ was added to $200 \mu \mathrm{L}$ cell suspension, incubated for 20 min, washed and re-suspended in $200 \mu \mathrm{L}$ binding buffer. Addition of $10 \mu \mathrm{L}$ propidium iodide [PI] $(20 \mu \mathrm{g} /$ $\mathrm{mL}$ ) was followed by FAC Scan analysis for apoptotic cell death. Cells fixed with $75 \%$ ice-cold ethanol at $-20^{\circ}$ $\mathrm{C}$ for 2 hours were stained with PI in the presence of
RNase A (100 $\mu \mathrm{g} / \mathrm{mL})$ for cell cycle analysis.

\section{AO or MDC vital staining}

In 96-well plates, the cells treated with vernolepin were stained with AO $(5 \mu \mathrm{g} / \mathrm{mL})$ or MDC $(0.05 \mathrm{mmol} / \mathrm{L})$ for $20 \mathrm{~min}$. We used fluorescence microscope (OLYMPUS IX71) for examination of the stained cells.

\section{Western blot analysis}

Following vernolepin treatment, the cells were lysed in lysis buffer $(150 \mu \mathrm{mol} / \mathrm{L} \mathrm{NaCl}, 50 \mu \mathrm{mol} / \mathrm{L}$ Tris- $\mathrm{HCl}$, $0.5 \%$ deoxycholic acid, $1 \%$ NP-40, $0.1 \%$ SDS and protease inhibitor cocktail) on ice for 1 hour. Bicinchoninic acid protein assay kit (Pierce) was used for determination of protein concentration after centrifugation of lysates. Proteins separated on SDS-PAGE were transferred to polyvinylidenedifluoride (PVDF) membrane blocked with a solution containing $10 \mu \mathrm{mol} / \mathrm{L}$ Tris, 150 $\mu \mathrm{mol} / \mathrm{L} \mathrm{NaCl}, 0.1 \%$ Tween 20 (TBS-T) and 5\% non-fat dry milk for 3 hours. After incubation with primary antibody at $4^{\circ} \mathrm{C}$ for 12 hours the membrane was treated with secondary antibody for 2 hours.

\section{Statistical analysis}

We used student's $t$ distribution probability density function for calculation of $P$-value. The experiments were performed in triplicates and expressed as mean \pm S.D. The differences were considered statistically significant at $\mathrm{p}<0.05$.

\section{Results}

Treatment of human ovarian carcinoma cell lines with vernolepin lead to inhibition of cell growth in a concentration and time dependent manner. Among the range of concentrations from 10 to $100 \mu \mathrm{M}$ tested the inhibition of cell growth was significant at $30 \mu \mathrm{M}$ of vernolepin after 48 hours in both OVCAR-3 and SK-OV3 cell lines (Figure 1A).

Analysis of cell cycle using PI staining and FACS showed an increase in the number of OVCAR-3 cells at G2/M phase $(18.2 \pm 1.9 \%$ to $39.2 \pm 2.1 \%)$ on vernolepin treatment after 48 hours. Similar cell cycle arrest was also detected in SK-OV3 cells $(15.0 \pm 1.0 \%$ to $47.7 \pm$ $2.4 \%$ ) at G2/M phase (Figure 1B).

Although no change in nuclei or nuclear membrane was noticed on vernolepin treatment in OVCAR-3 cells but a number of membranous structures and vacuoles were visible in the cytoplasm after 24 hours. After 48 hours chromatin condensation and nuclear fragmentation indicating typical apoptotic changes was clearly visible (Figure 2A).

There was only cytoplasmic vacuolization with no chromatin condensation in the vernolepin-treated SKOV3 cells for 24 hours. Autophagosomes were also 


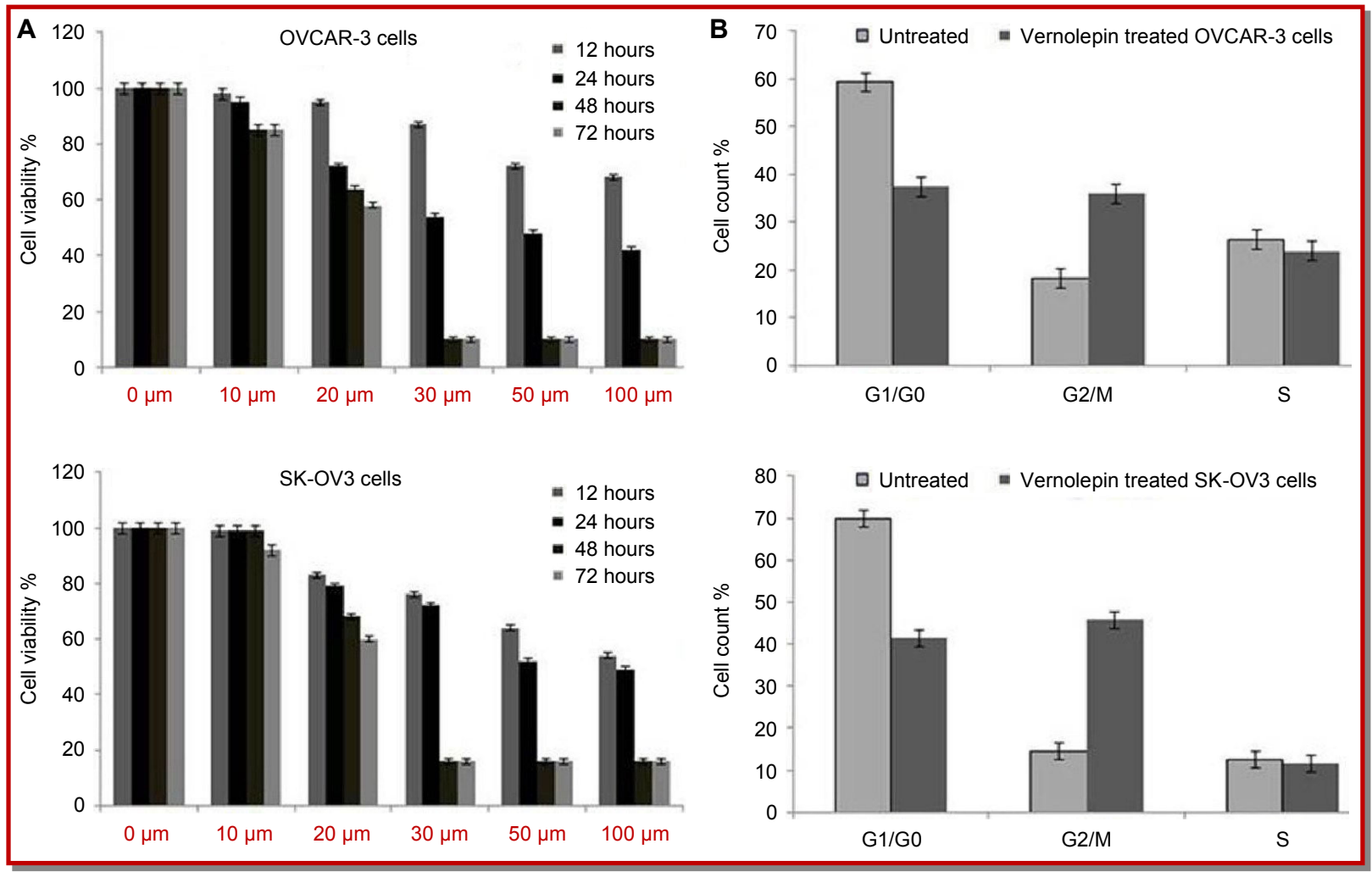

Figure 1: (A) Vernolepin inhibited the proliferation of ovarian cancer cells; (B) Cell cycle was arrested at G2/M phase by vernolepin. The data are presented as means \pm S.D. from three independent experiments

observed in the cytoplasm, which contained portions of cytosol and organelles, such as endoplasmic reticulum (ER) and mitochondria (Figure 2B).

In vernolepin-treated OVCAR-3 cells red fluorescent spots whereas in control cells and the cells co-treated with $5 \mu \mathrm{mol} / \mathrm{L} 3-\mathrm{MA}$ plus vernolepin green fluorescence was observed on $\mathrm{AO}$ staining. In vernolepintreated OVCAR-3 cells accumulation of autophage specific staining MDC was also observed around the nuclei (Figure 3).

OVCAR-3 cells on starvation (in EBSS medium) for 4 hours, exhibited reduction in cell viability to $66.9 \%$. Similarly treatment of OVCAR-3 cells with $5 \mu \mathrm{mol} / \mathrm{L} \mathrm{3-}$ MA decreased cell viability to $76.2 \%$ (Figure 4). Vernolepin treatment lead to $83.6 \%$ cell viability compared to control. However the cell viability was increased to $93.7 \%$ on treatment with 2 hour starvation followed by 48 hours vernolepin treatment. On the other hand, 3MA $(2 \mu \mathrm{mol} / \mathrm{L})$ in combination with vernolepin decreased cell viability to $54.5 \%$ (Figure 4 ). These results demonstrate that in vernolepin-treated OVCAR-3 cells autophagy exerts protective effect.

The results from DAPI staining revealed typical apoptotic changes with chromatin condensation and nuclear fragmentation in OVCAR-3 cells at 48 hours of vernolepin treatment. Annexin V-FITC/PI staining and FACS demonstrated that in OVCAR-3 cells treatment with 30 $\mu \mathrm{M}$ vernolepin for 48 hours caused $34.2 \%$ of the cells to undergo apoptosis compared to $3.5 \%$ in control. Similarly treatment with $30 \mu \mathrm{M}$ vernolepin for 48 hours caused $28.5 \%$ SK-OV3 cells to undergo apoptosis compared to $2.7 \%$ in control (Figure 5).

\section{Discussion}

The present study demonstrates that vernolepin treatment inhibits cell proliferation, arrests G2/M phase of cell cycle and induces the formation of AVOs in OVCAR-3 and SK-OV3 cancer cells. We also observed a large number of double-membrane autophagosomes and PAS in both OVCAR-3 and SK-OV3 ovarian cancer cell after vernolepin treatment. In addition, ovarian cancer cells on co-treatment with 3-MA and vernolepin, showed that 3-MA could reverse the accumulation of MDC and AO. All these results indicated that 3-MA could specifically inhibit vernolepin-induced autophagy in ovarian cancer cells by inhibiting the increase of LC3.

Recently, radiation (Paglin et al., 2001), ceramide (Daido et al., 2004), rapamycin (Takeuchi et al., 2005), and arsenic trioxide (Kanzawa et al., 2003) have been reported to act as stimulants for the autophagic process. The results from our study revealed that autophagy could play a protective role in vernolepin-treated 


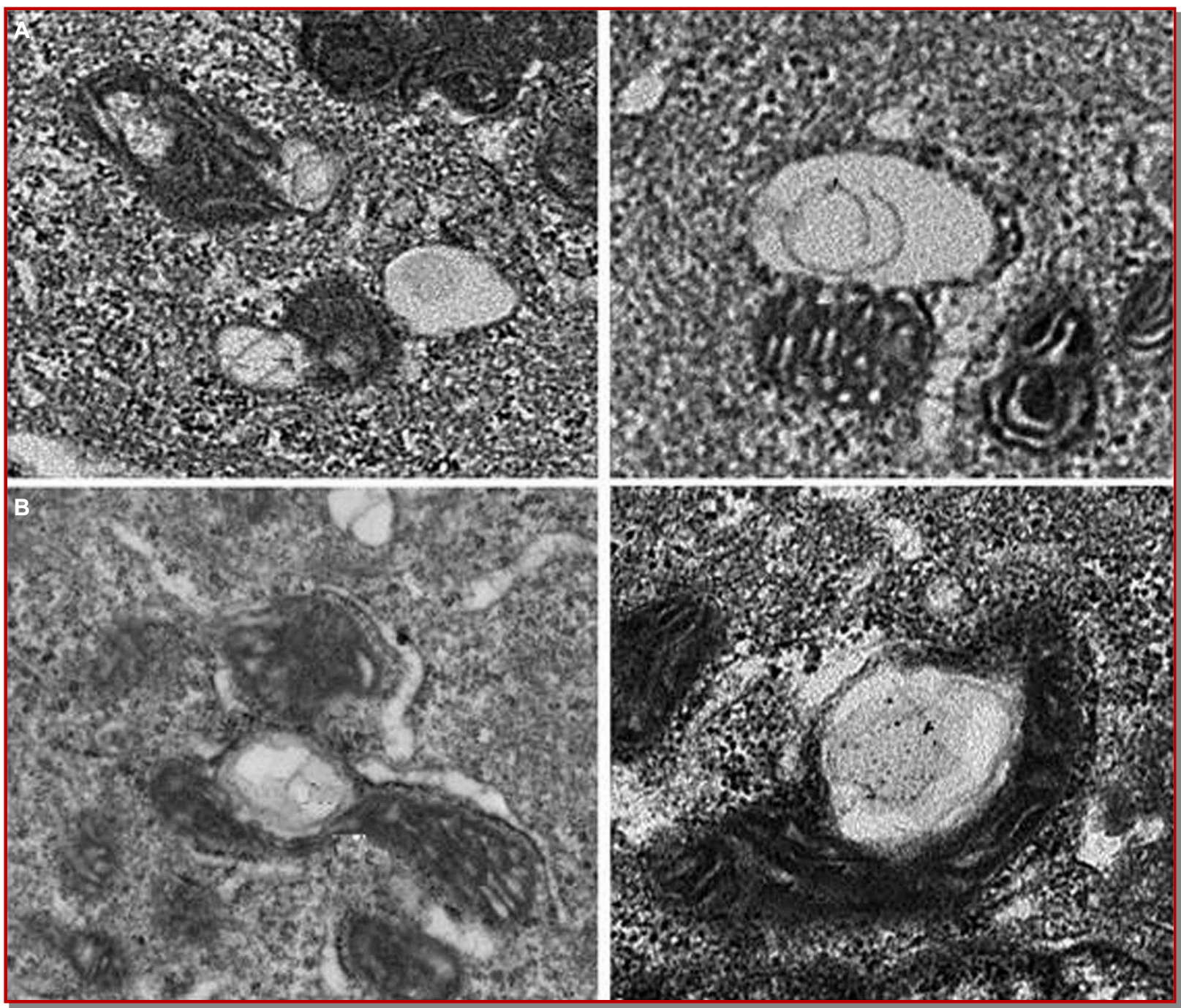

Figure 2: Formation of autophagosomes was induced by vernolepin in ovarian cancer cells. OVCAR-3 (A); and SK-OV3 (B) cells were treated with vernolepin $(30 \mu \mathrm{M})$ or DMSO

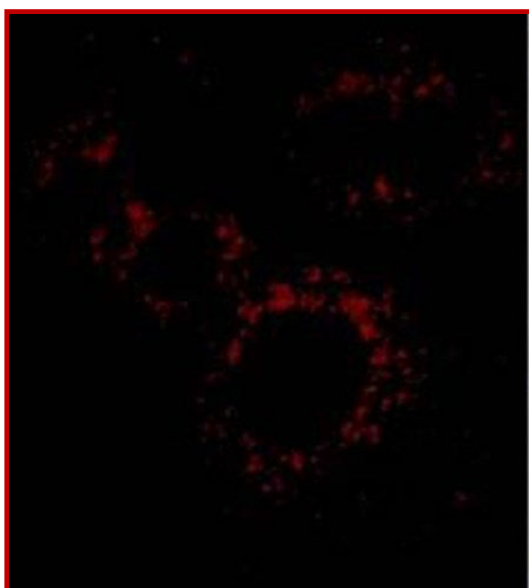

Vernolepin

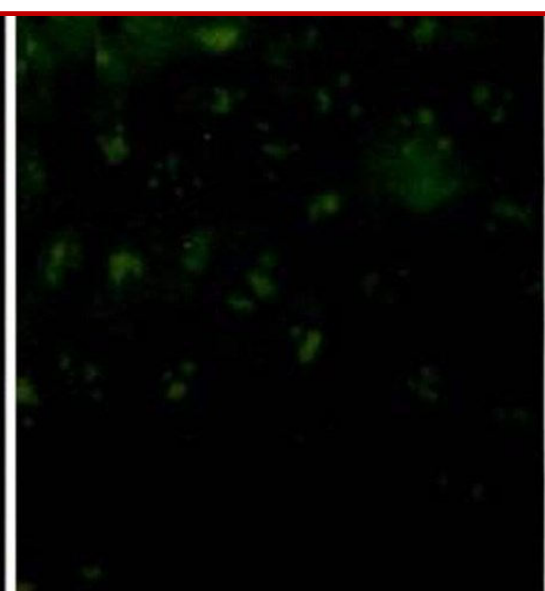

Control

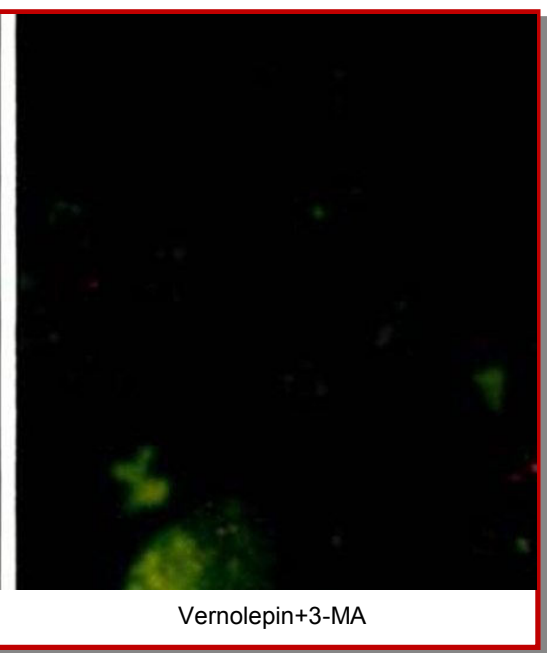

Figure 3: Accumulation of AVOs induced by vernolepin treatment 


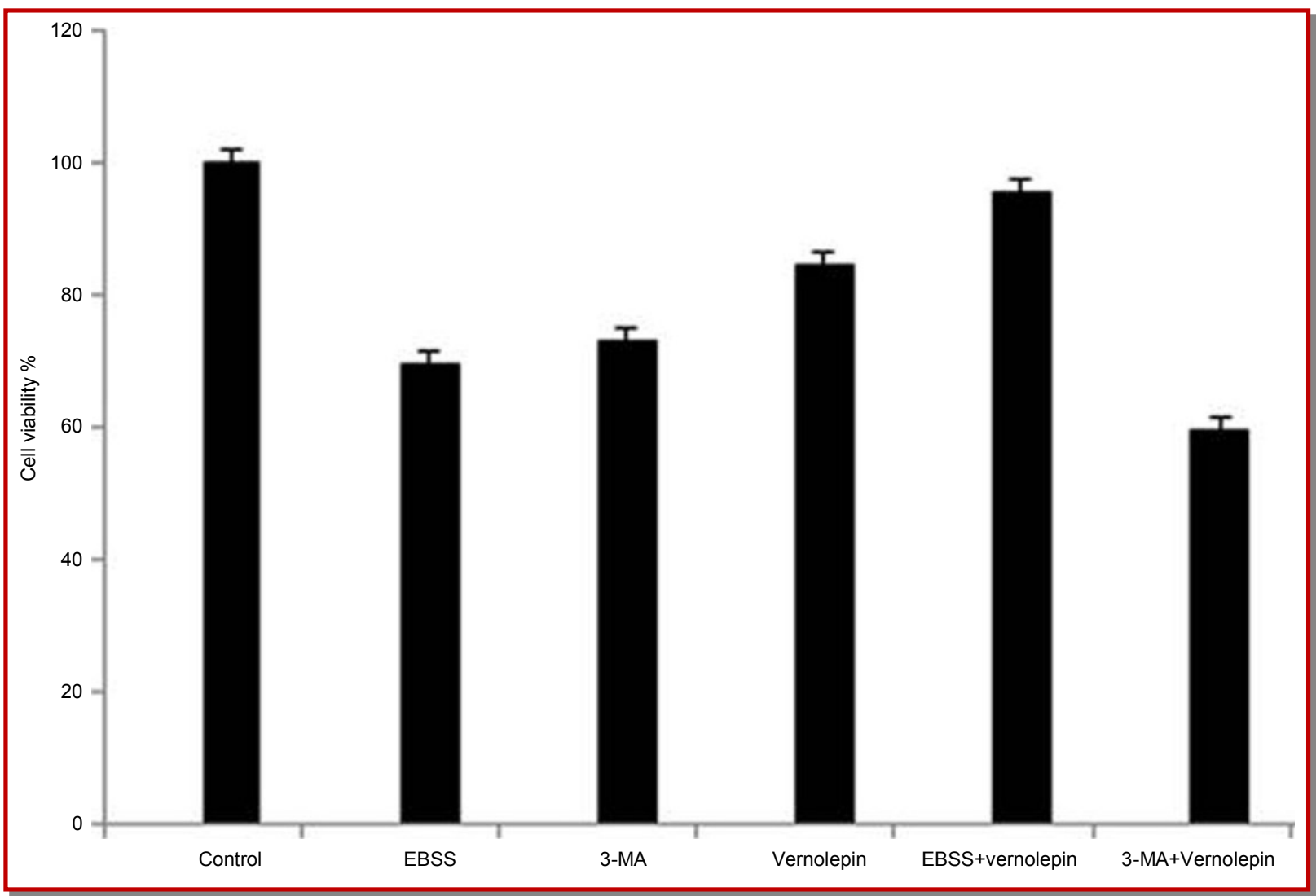

Figure 4: Protective role of autophagy in vernolepin-treated OVCAR-3 cells

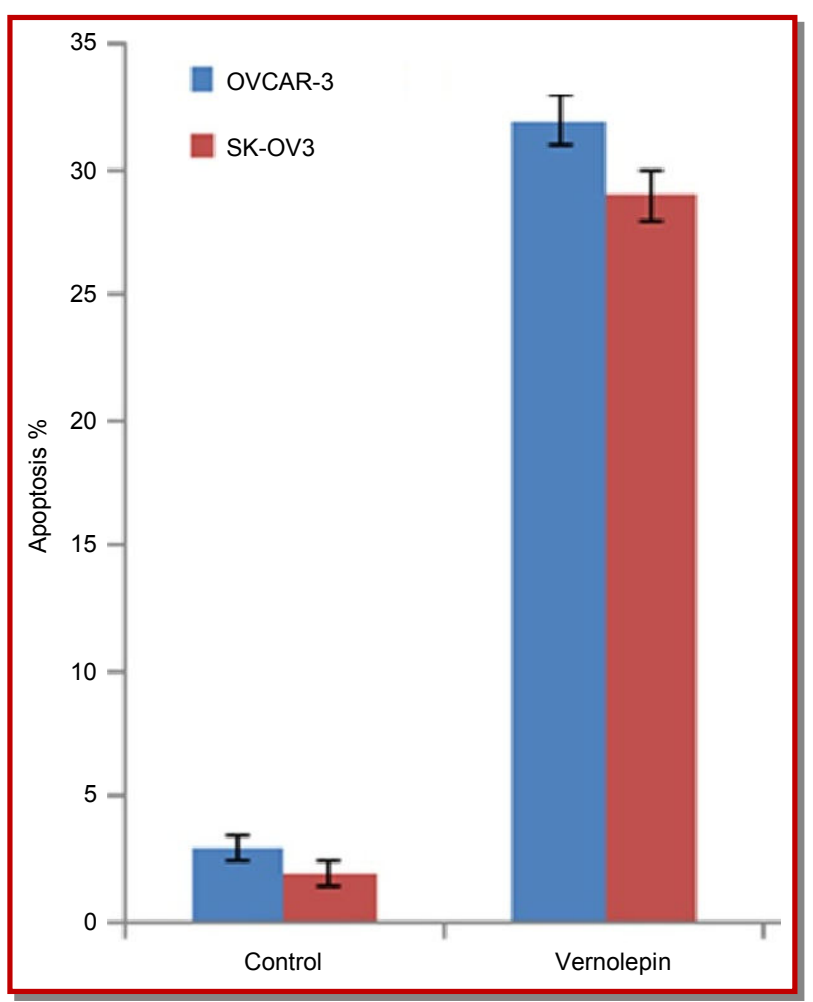

Figure 5: Vernolepin induced apoptosis in ovarian cancer cells after 48 hours treatment ovarian cancer cells. Nutrient starvation has been widely used to induce autophagy (Martinez-Borra and Lopez-Larrea, 2012). OVCAR-3 cells on co-treatment with starvation and vernolepin exhibited high level of autophagy compared to the cells treated with vernolepin alone. However, there was increased vernolepininduced cell death on treatment with 3-MA. Vernolepin treatment for 48 hours significantly increased apoptosis in OVCAR-3 and SK-OV3 cells. There was chromatin condensation, nuclear fragmentation and disappearance of the surface microvilli in the cells undergoing apoptosis.

In summary, we demonstrated that vernolepin treatment could induce autophagy in ovarian cancer cells. Autophagy could protect cancer cells from apoptotic cell death by delaying the onset of apoptosis. P21 protein plays an important role in vernolepin-induced autophagy and apoptosis.

\section{References}

Baehrecke EH. Autophagy: Dual roles in life and death? Nat Rev Mol Cell Biol. 2005; 6: 505-10.

Bast RC Jr. Status of tumor markers in ovarian cancer screening. J Clin Oncol. 2003; 21: 200s-05s. 
Chan JK, Cheung MK, Husain A, Teng NN, West D, Whittemore AS, Berek JS, Osann K. Patterns and progress in ovarian cancer over 14 years. Obstet Gynecol. 2006; 108: 52128.

Clayde J. Organic chemistry. Oxford, Oxford University Press, 2005, p 238.

Daido S, Kanzawa T, Yamamoto A, et al. Pivotal role of the cell death factor BNIP3 in ceramide-induced autophagic cell death in malignant glioma cells. Cancer Res. 2004; 64: 428693.

Eisenkop SM, Spirtos NM, Friedman RL, Lin WC, Pisani AL, Perticucci S. Relative influences of tumor volume before surgery and the cytoreductive outcome surviva for patients with advanced ovarian cancer: A prospective study. Gynecol Oncol. 2003; 90: 390-96.

Hartge P, Whittemore AS, Itnyre J, McGowan L, Cramer D.Rates and risks of ovarian cancer in subgroups of white women in the United States. The Collaborative ovarian Cancer Group. Obstet Gynecol. 1994; 84: 760-64.

Hoskins WJ. Prospective on ovarian cancer: Why prevent? J Cell Biochem. 1995; 23(Suppl): 189-99.

Kanzawa T, Kondo Y, Ito H, et al. Induction of autophagic cell death in malignant glioma cells by arsenic trioxide. Cancer Res. 2003; 63: 2103-08.

Laekeman GM, Mertens J, Totté J, Bult H, Vlietinck AJ, Herman AG. Isolation and pharmacological characterization of vernolepin. J Nat Prod. 1983; 46: 161-69.

Laekeman GM, Clerck F, Vlietinck AJ, Herman AG. Vernolepin: An antiplatelet compound of natural origin. NaunynSchmiedeberg's Arch Pharmacol. 1985; 331: 108-13.

Martinez-Borra J, Lopez-Larrea C. Autophagy and self-defense. Adv Exp Med Biol. 2012; 738: 169-84.

McGuire WP, Hoskins WJ, Brady MF, Kucera PR, Partridge EE, Look KY, Clarke-Pearson DL, Davidson M. Cyclophosphamide and cisplatincompared with paclitaxel and cisplatin in patients with stage III and stage IV ovarian cancer. N Engl J Med 1996; 334: 1-6.
Ozols RF, Bundy BN, Greer BE, Fowler JM, Clarke-Pearson D, Burger RA, Mannel RS, DeGeest K, Hartenbach EM, Baergen R. Phase III trial of carboplatin and paclitaxel compared with cisplatinand paclitaxel in patients with optimally resected stage III ovarian cancer: A Gynecologic Oncology Group study. J Clin Oncol. 2003; 21: 3194-200.

Paglin S, Hollister T, Delohery T, et al. A novel response of cancer cells to radiation involves autophagy and formation of acidic vesicles. Cancer Res. 2001; 61: 439-44.

Previati M, Lanzoni I, Corbacella E, et al. Cisplatin-induced apoptosis in human promyelocyticleukemia cells. Int J Mol Med. 2006; 18: 511-16.

Stewart JJ, White JT, Yan X, et al. Proteins associated with Cisplatin resistance in ovarian cancer cells identified by quantitative proteomic technology and integrated with mRNA expression levels. Mol Cell Proteomics 2006; 5: 433 43

Terman A, Gustafsson B, Brunk UT. Autophagy, organelles and ageing. J Pathol. 2007; 211: 134-43.

Toth S, Nagy K, Palfia Z, et al. Cellular autophagic capacity changes during azaserine-induced tumour progression in the rat pancreas: Up-regulation in all premalignant stages and down-regulation with loss of cycloheximide sensitivity of segregation along with malignant transformation. Cell Tissue Res. 2002; 309: 409-16.

Takeuchi H, Kondo Y, Fujiwara K, et al. Synergistic augmentation of rapamycin-induced autophagy in malignant glioma cells by phosphatidylinositol 3-kinase/protein kinase B inhibitors. Cancer Res. 2005; 65: 3336-46.

Van Dalen A, Favier J, Burges A, Hasholzner U, de Bruijn HW, Dobler-Girdziunaite D, Dombi VH, Fink D, Giai M, McGing P, Harlozinska A, Kainz C, Markowska J, Molina R, Sturgeon C, Bowman A, Einarsson R. Prognostic significance of CA 125 and TPS levels after 3 chemotherapy courses in ovarian cancer patients. Gynecol Oncol. 2000; 79: 444-50.

Wu YT, Tan HL, Huang Q, et al. Autophagy plays a protective role during zVAD-induced necrotic cell death. Autophagy 2008; 4: 457-66.

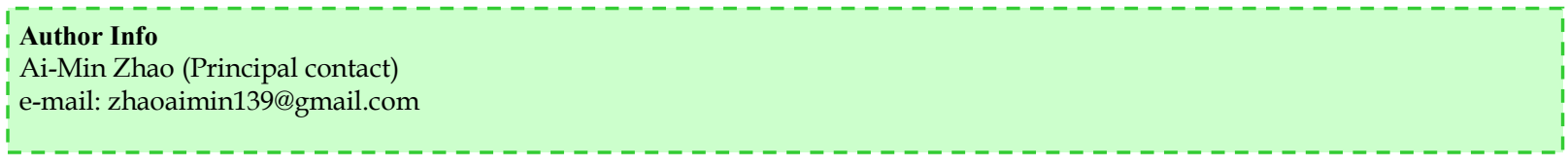




\section{Your feedback about this paper}

1. Number of times you have read this paper 0

2. Quality of paper Click

3. Your comments

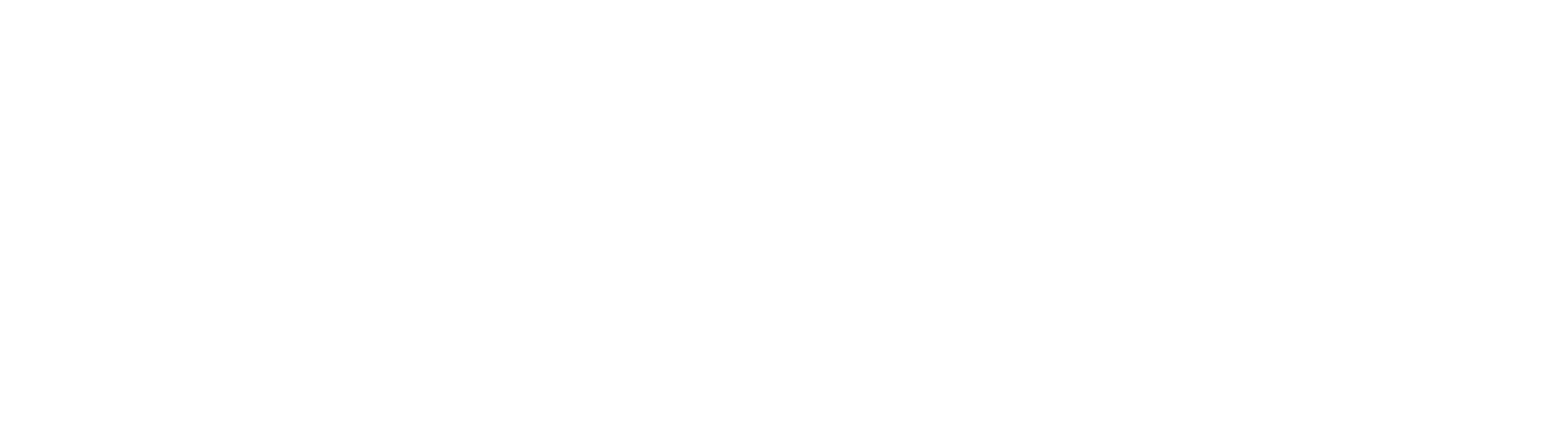

